\title{
Stochastic Analysis of the Break-Even of the Enterprise
}

\author{
Belykh, Vasiliy V. \\ Candidate of Physico-Mathematical Sciences, Associate Professor at the Department of Economics, \\ Corporate Management and Finance, \\ Novosibirsk State University of Economics and Management \\ 56, Kamenskaya St., Novosibirsk, \\ E-mail: v.v.belykh@gmail.com
}

\begin{abstract}
The break-even equation describes the relationship between the financial indicators of a company at various levels of production and sales. The processes that lead to their change are considered deterministic. In this paper, we present a mathematical model that complements the break-even analysis by including the uncertainty related to the operating activity of the company. The method is based on the description of the revenue generation process using the geometric stochastic motion model. In addition to that, to more accurately describe the impact of time we used the concept of the operational cycle. The equations that we obtained allow us to describe the financial result as a difference in the mathematical expectations of profit and loss. This method presents the structure of the financial result in terms of possible favorable and unfavorable outcomes, including into the analysis the alternative scenarios of company's development In addition to the theoretical research, we show to what extent the uncertainty of revenue affects the financial performance of a stable operating company. For this purpose, we consider the charts of the probability density functions of the parameters used in the break-even analysis which demonstrate the contribution of the random component on their magnitude. We will see that the conclusions made with regard to the stochastic nature of the proceeds may differ significantly from the results of the break-even analysis performed on the basis of the assumption of the deterministic nature of the proceeding processes. Within the framework of this paper, the operation of a company is considered primarily from the position of a breakeven analysis. However, the equations that were obtained can be used to calculate the indicators that allow to assess the risks of operating activities. This is shown in the interpretation of the model in terms of the options and calculation of return on equity, taking into account the risk.
\end{abstract}

Keywords: Break-even analysis; operating cycle; expectation and probability of profit and loss; the value of the option; the break-even point.

JEL: C67, G31, M21 


\section{Introduction}

Operating activities of the company has been facing surprises that are difficult to envisage. The degree of uncertainty increases during periods of recession. This takes place both at the industry level - in some industries things are going well, and others are experiencing difficulties, and at the company level - the uncertainty of returns and sales growth rate increases [Bloom, 2016]. Break-even analysis is one of the main methods used in the planning of production activities. The question is: how can we account for the uncertainty of operating activities? Some insights into this are provided by management methods applied in conditions where the quantity demanded can only be estimated approximately. The first section of the work deals with several such methods. This will allow us to identify variables related to uncertainty. Further, it will be shown how they determine the value of the random component in the break-even equation.

Our mathematical model complements break-even analysis. With its help, alternative scenarios for the development of the company are introduced into the range of issues under consideration. In this regard, the next section of the work is the main one. Here, revenue is considered as the result of a random process, to describe which a geometric random motion model can be applied. This approach allows us to estimate the mathematical expectations of profit and loss associated with the implementation of production plans. The financial result is given as a sum of these values. To better understand the approach used, we describe the proposed model in terms of options. Note that there are a significant number of models based on the use of the concept of real options. This concept has been successfully applied to address issues related to the analysis of investments in natural resources [Brennan, Schwartz, 1985] and the assessment of the value of deferring investment time [McDonald, Siegel, 1986]. Although the area of its application is much broader, the list given corresponds to the fact that real options are largely a tool for solving tasks associated with investing [Bukhvalov, 2004], and not with the operating activities of companies.

Uncertainty is the cause of the company's instability. The deviation of financial ratios from normative values can be a sign of approaching bankruptcy [Fedorova, Timofeev, 2015]. This method of the sustainability assessment is based on the results of econometric studies of a sample of companies belonging to a particular industry. Another approach is used in the work. The approach uses data that come under one company. We will graphically show the range in which the random component in the break-even equation is most significant. We correlate the operating profit with random fluctuations in revenue. We will consider what determines the rate of the transition from a definite loss to a definite profit. The analysis of the effect of the density function asymmetry on the break-even point will be provided. In the framework of the stochastic approach, all indicators used in the management of the company under uncertainty will be analyzed. Previously disparate, they are now considered collectively as variables of the same equation. It will become clear how their combination determines the effect of uncertainty on operating profit.

The key condition of the stochastic approach is that the company's performance, calculated on the basis of revenue, should be taken as random variables. To a large extent, this approach relies on econometric analysis. At the individual firm level, econometrics opportunities are reduced. This is due to the relatively small amount of experimental data that we have in such studies - it is limited to the number of accounting reports. However, the final section of the work deals with the distribution density of indicators used in the break-even analysis. This makes it clear to what extent their value is random. By the example of the selected company, it has demonstrated how to use the equations we have obtained. All calculations are made taking into account the dominant influence of the random component. The Appendixes to the work contain materials explaining some of the issues related to the justification of the model and its use to assess the risk of operating activities.

\section{Management methods under uncertainty}

The level of operating uncertainty can be measured on the basis of the reliability of the revenue forecasts available to the company. Changes in prices and sales volumes of products occur under external influence, which limits the degree of control of these indicators. One approach is to reduce the magnitude of random fluctuations in revenue. By making calculations based on incremental data, it is possible to calculate the amount of break-even change in sales volume when the price changes and to compensate for the loss of income associated with the "price effect", the additional income from the "volume effect" [Shigaev, 2008]. The method can be used both in case of adverse changes in market conditions (in the case of a reduction in the price of products) and in the event of favorable changes (price increase). As a result, revenue uncertainty is reduced.

Uncertainty in the forecast affects the production processes. In this case, the company faces the challenge of producing products in an environment where there is uncertainty about demand. Since the decision on production volumes is made at the beginning of the planning period, and information on actual demand comes later, there is a need to have a mechanism to regulate the ratio of current operating expenses to expected future revenue. To solve this problem, it is proposed to apply an algorithm based on the feedback principle - at each planning step, information about the available stock of finished products and actual demand are used to adjust the production activity of the future period [Bukhvalova, Petrusevich, 2011]. Note that this management method has an impact on the uncertainty characteristic associated with time, reducing the variance of the revenue growth rate with the planning period increase. 
Figure 1. Indicators characterizing management methods under uncertainty

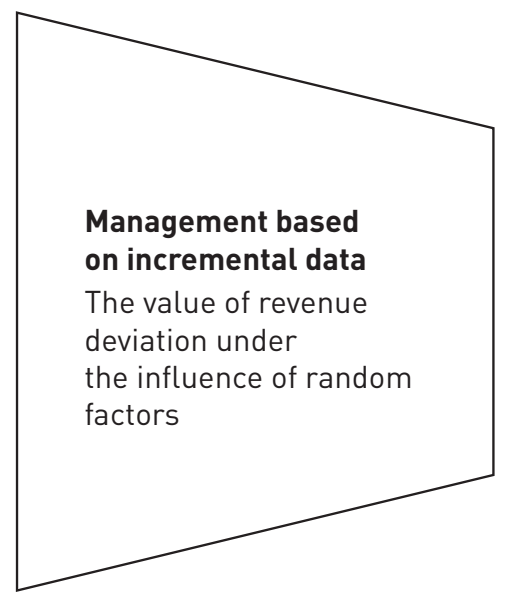

The influence of random factors is not always negative, another feature of uncertainty is manifested in the potential profit growth. Thus, decisions made require criteria that take into account both the threats and the opportunities associated with the situation of uncertainty. In view of this rule, the management of the company's production activity has been developed as a process, the input of which provides for purchased physical resources, and the output - the final product [Madera, 2015]. It is assumed that production is carried out in an environment where there is an uncertainty in the company regarding the quantity demanded for its products and the availability of production factors. To choose the best solution, it is proposed to use the criterion "odds-to-risk ratio" The value of this indicator shows the probability of actualization in the future of various events, which in the case of a favorable nature are odds, otherwise - risks. The choice of decision is based on the ratio of favorable and unfavorable outcomes.

The use of these methods contributes to lower level of uncertainty. If we place the models by the publication time of the relevant work, then we get a list of indicators describing the effect of uncertainty with the increasingly high degree of generalization (Fig. 1). Such a presentation is not a classification in the full sense of the word, but conveys levels at which the random nature of demand manifests itself. This still leaves open the issue of the mechanism by which it would be possible to combine variables that are significant when using a particular management method. One of the objectives of our study is to derive an analytic expression describing the relationship between operating profit and indicators characterizing uncertainty. The following econometric analysis is an example of the practical application of the proposed model.

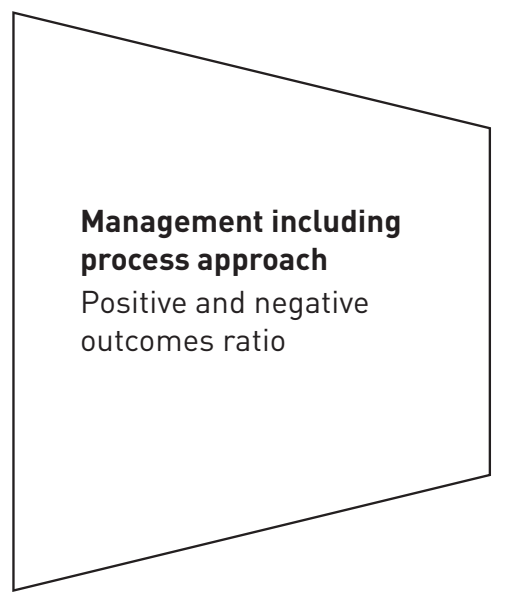

\section{Mathematical model}

The break-even analysis studies the relationship of profit, revenue and expenses at different levels of production and sales. In terms of inventory turnover, the financial result is a consequence of the implementation of a number of operating cycles ${ }^{1}$. We will supplement the break-even equation with an indication of the point in time to which certain indicator relates with respect to the operating cycle:

$E B I T_{t}=V_{t}-\left(F C_{0}+V C_{0}\right) \cdot e^{\mu \cdot t}=V_{t}-K_{0} \cdot e^{\mu \cdot t}=V_{t}-K_{t}(1)$ where EBITt and $V t$ are the operating profit and revenue which the company expects to receive after the time $t$ equal to the operating cycle duration;

$K_{0}$ is the sum of fixed $\left(F C_{0}\right)$ and variable $\left(V C_{0}\right)$ expenses incurred at the beginning of the operating cycle; $K t=K_{0} \cdot e^{\mu t}$ is the estimated value of expenses at the end of the operating cycle, calculated at the rate of continuously accrued interest $\mu$.

In view of the uncertainty of demand, we represent the sale proceeds as a random process $S_{t}$, corresponding to the geometric Brownian motion [Shiryaev, 1998, p. 290]²:

$S_{t}=S_{0} \cdot e^{\sigma \cdot W_{t}+\left(\mu-\frac{\sigma^{2}}{2}\right) \cdot t}$,

where $S_{t}$ and $S_{0}$ are the revenue at time $t$ and at the initial time point;

$\sigma$ is the standard deviation of the logarithm of the revenue growth rate (over year);

$W_{t}$ is the standard Brownian motion; $\mu$ is the expected logarithm of the revenue growth rate with a standard deviation equal to zero (over year); $t$ is the random process development time (in terms of year).

\footnotetext{
${ }^{1}$ Note that the sequence of cycles relative to each other is not essential. It can be imagined that the operational cycle corresponds to the test in probability theory. The regularities that manifest themselves in the tests do not depend on whether they are obtained on the basis of several consecutive tests or on the basis of many simultaneously performed tests. Upon completion of the operating cycle (testing), the company may make both profit and loss.

${ }^{2}$ More precisely, the process of revenue generation can be described by the Ornstein-Uhlenbeck process, for which a geometric Brownian motion is a particular case. It is important for us that in both cases, the distribution density of the logarithm of the revenue growth rate is subject to a log-normal law.
} 
In this case, the value of $V_{t}$ in equation (1) will correspond to the mathematical expectation (average value) of a random process:

$V_{t}=E\left(S_{t}\right)=\int_{0}^{+\infty} s \cdot \omega(s, t) d s$,

where $s$ is the possible values of the random variable; $\omega(s, t)$ is the distribution density of the cross section of the random process $S_{t}$ at time $t$. The time parameter used in describing the distribution density indicates the relationship between the distribution law and the operating cycle duration.

In the same way we describe the operating profit, presenting its mathematical expectation as the difference, the first term of which corresponds to the expectation of profit, and the second - of loss:

$$
\begin{aligned}
& E B I T_{t}=\int_{0}^{+\infty}\left(s-K_{t}\right) \cdot \omega(s, t) d s= \\
& =\int_{K_{t}}^{+\infty}\left(s-K_{t}\right) \cdot \omega(s, t) d s-\int_{0}^{K_{t}}\left(K_{t}-s\right) \cdot \omega(s, t) d s=, \\
& =C_{t}-P_{t}
\end{aligned}
$$

where $C_{t}$ is the mathematical expectation of profit; $P_{t}$ is the mathematical expectation of loss. The designations of these values are given with the time $t$ parameter, since they describe the financial result of the company at the end of the operating cycle.

Equation (4) represents the operating profit as the result of implementation of a number of operating cycles, each of which ends with a random event - with a positive or negative financial result; therefore, we call it the stochastic break-even equation.

For geometric random motion, the distribution density $\omega(s, t)$ is described by a log-normal law, which allows us to find the integrals included in equation (4) [Hull, 2002, p. 262$]^{3}$.

Taking into account that the mathematical expectations of profit and loss are calculated at the moment of the end of the operating cycle, we obtain the following equations for calculating these values (Appendix 1):

- $\quad$ expectation of profit is:

$C_{t}=V_{t} \cdot N\left(d_{1}\right)-K_{t} \cdot N\left(d_{2}\right)$;

- expectation of loss is:

$P_{t}=V_{t} \cdot\left(N\left(d_{1}\right)-1\right)-K_{t} \cdot\left(N\left(d_{2}\right)-1\right)=$

$=C_{t}-\left(V_{t}-K_{t}\right)=C_{t}-E B I T_{t}$

The integral normal distribution functions $N(d 1)$ and $N(d 2)$ have arguments equal to:

$d_{1}=\frac{\ln \left(\frac{V_{t}}{K_{t}}\right)+\frac{\sigma_{t}^{2}}{2}}{\sigma}$ and, $d_{2}=\frac{\ln \left(\frac{V_{t}}{K_{t}}\right)-\frac{\sigma_{t}^{2}}{2}}{\sigma_{t}}=d_{1}-\sigma_{t}$ where $\sigma_{t}$ is the standard deviation of the logarithm of the revenue growth rate for a period of time equal to the operating cycle duration.

In accordance with the geometric Brownian motion model, standard deviations, describing the same random process for two varying periods of time $t_{1}$ and $t_{2}$, are related to each other as follows:

$\frac{\sigma_{t_{1}}}{\sigma_{t_{2}}}=\sqrt{\frac{t_{1}}{t_{2}}}$.

Thus, if we know the standard deviation for a period of time equal to a year, then we can calculate the value of the indicator for a period of time equal to the duration of the operating cycle.

The analytical expressions obtained by us include variables taken into account when considering decision-making methods under uncertainty.

\section{Description in Terms of Options}

It is not hard to see that expressions (5) and (6) are similar to the equations used to calculate the value of options (see Appendix 1). This makes it possible to describe our model in terms of options.

Previously, the option pricing model was applied to study the risk structure of company's debt obligations [Merton, 1974], but it is not easy to extend it to the operating activities risk assessment. One of the main difficulties is related to the asymmetric distribution of rights and obligations - holding an option grants rights, but does not impose obligations. Usually this condition is met through allocating rights and obligations between different parties to the transaction, for example, between shareholders and creditors. When considering the operating activities it cannot be done, since the subject of consideration is not a transaction.

The method that makes it possible to apply an option model to the assessment of risk associated with the company's operating activities is based on the division of sources used to finance the company's current activities into two types. The first type is the funds derived by the company from the sale of its products and services, the second - sources not related to its operating activities (equity, loans).

We will present the financial result as the value of a portfolio consisting of a long call option and a short put. The underlying asset of options in our case is the revenue $S_{t}$. Expenses $K_{t}$ associated with the receipt of revenue corresponds to the option exercise price of performance. The value of each of the options depends on the revenue-to-expenses ratio. The graph shows how the portfolio value (financial result) is the sum of the value of the positions of the call option buyer (profit) and the put option seller (loss), with different levels of revenue uncertainty (Fig. 2).

\footnotetext{
${ }^{3}$ It is possible to find integrals for the distribution density described by a normal law, but such a description will be less accurate than a log-normal distribution (Appendix 2)
} 
The company's profit is equal to the value of the call option. The option buyer acquires the right to compensation for expenses $K_{t}$ from funds received as a result of operating activities. The company becomes the holder of the option at the time of the acquisition of raw materials. The option will be exercised if the sale proceeds are higher than the expenses. The term of the option ends at the time of product sales, which corresponds to the time of completion of the operating cycle.

The company's loss is equal to the value of the put option. The option seller acquires the obligation to cover expenses $K_{t}$ from funds not related to operating activities. The company becomes a seller of the put option simultaneously with the acquisition of the call option. The option will be exercised if the selling price of the product is lower than the cost price. The term of the option also ends at the time of product sales.

Figure 2. The financial result and the value of options

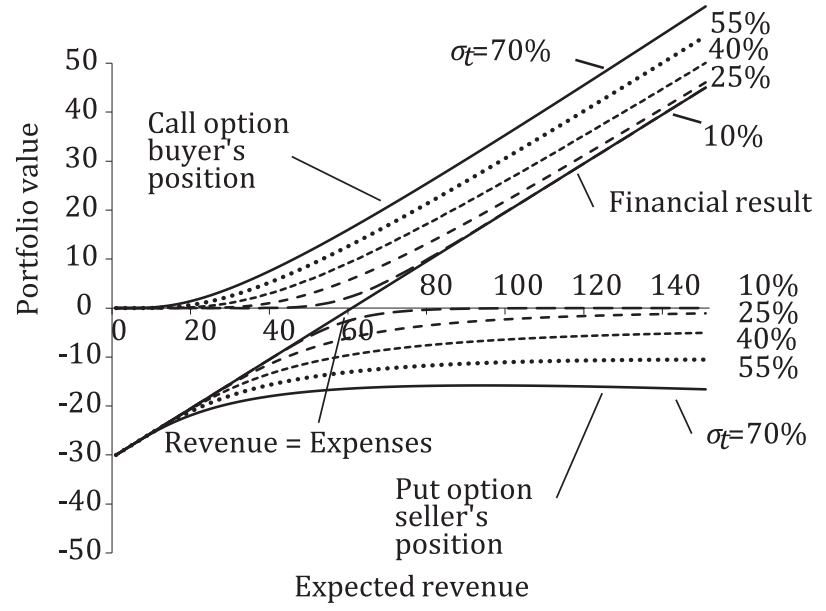

\section{Effects of Uncertainty}

According to the concept of the operating cycle [Richards, Laughlin, 1980], production activities begin with the acquisition of raw materials and materials necessary for production. At this time, the level of demand is not exactly known and revenue can be considered as a random variable. The operating profit that a company receives at the end of an operating cycle is a linear function of this random variable. In accordance with the deterministic break-even equation (1), the expectation of operating profit equals the difference between the mathematical expectation of revenue and expenses incurred. In accordance with the stochastic break-even equation (4), the mathematical expectation of operating profit equals the difference of the mathematical expectations of a positive and a negative financial result.

We'll graphically represent the ratio of the variables included into the deterministic and stochastic break-even equations (Fig. 3). Deterministic indicators are given in the form of linear relationships that give their value at different production and sales volumes ${ }^{4}$. Dotted curves refer to the stochastic equation. The distance between them and the cost line shows the mathematical expectation of profit (upper chart) and of loss (lower chart). As they move away from the break-even point, these charts asymptotically merge with revenue and expenses lines, showing the range in which the effect of uncertainty manifests itself. How they run with different values of standard deviation can be seen in Fig. 2. The break-even chart is supplemented with the revenue distribution curve $\omega(s, t)$ used in the calculation of mathematical expectations (the log-normal distribution density is shown).

The density function describes the frequency and range of random fluctuations in revenue around the level set by the production and sale of the planned product volume. The area of the painted figure is proportional to the probability of receiving revenue in an amount less than the expenses incurred. The given example shows that it is possible to have a considerable margin of financial strength, but at the same time the probability of obtaining a negative financial result will remain significant. This is due to the fact that the loss probability is not contingent upon the extent to which current revenue differs from its value at the break-even point, but upon the ratio of the standard deviation of revenue and expected operating profit.

One can see the asymmetry of the revenue distribution curve $\omega(s, t)$ (see Fig. 3). This means that the numerical characteristics of a random variable: the mathematical expectation $\left(V_{t}\right)$, the median $\left(S_{0.5,} t\right)$ and the mode $\left(\hat{S}_{t}\right)$ do not coincide with each other. For the log-normal distribution, their relationship is described by the inequality: $V t>$ $S_{0.5, t}>\hat{S}_{t}$. It increases with $\sigma_{t}$ growth. This leads to the fact that with an increase in uncertainty, the breakeven point, calculated on the basis of the mathematical expectation, becomes less representative.

Let's look at how the probability of favorable outcomes $P\left\{S_{t}>K_{t}\right\}$ changes at the break-even point (Fig. 4). This probability is equal to the value of the integral function of the normal distribution $N\left(d_{2}\right)$. It determines the frequency with which operating cycles end with a positive financial result. The charts show the change in the probability of making a profit, depending on the expected revenue $V_{t}$ and expenses $K_{t}$ ratio. It can be seen how the rate of transition from a definite loss to a definite profit decreases with an increase in the standard deviation of the logarithm of the revenue growth rate.

The asymmetry of the function $\omega(s, t)$ leads to the fact that at the break-even point the probability of making a profit is less than the probability of making a loss (this fact is clearly seen in the graph $P\left\{S_{t}>K_{t}\right\}$ for $\sigma \mathrm{t}=25 \%$ in Figure 4).

\footnotetext{
$4 \quad$ For clarity, we used an example that relies on the straight-line nature of the relationship between revenues and expenses and the number of produced and sold products. At the same time, the mathematical model described in this paper does not contain such restrictions. The nature of the revenue and expenses relationship can be of any kind. For example, such as in the work [Madera, 2015], which assumes an increase in variable costs per unit of product with an increase in production. What matters is how the relationships mentioned affect the standard deviation of the logarithm of the revenue growth rate and the amount of expenses.
} 
This means that more than half of operating cycles with this revenue-to-expenses ratio will be unprofitable. At the same time, the average profit that a company makes with a favorable completion of the operating cycle is greater than the average loss it makes with an unfavorable outcome. As a result, the mathematical expectations of profit and loss are the same. The most noticeable point on the graph $\omega(s, t)$ is the mode which shows the most probable value of revenue: $\omega(\hat{S}, t)=\max \omega(s, t)$. According to the properties of the log-normal law, the mode-to-expectation ratio is described by the equation: $\hat{\mathrm{S}}_{t}=V t \cdot \exp \left(-1.5 \sigma \mathrm{t}^{2}\right)$. The value of revenue equal to the mode determines the most probable value of operating profit that a company can make upon completion of the operating cycle. The level of production and sales, at which the $K_{t}=\hat{\mathrm{S}}_{t}$ holds, can be defined as the most probable break-even point.

Figure 3. Break-even chart ${ }^{5}$

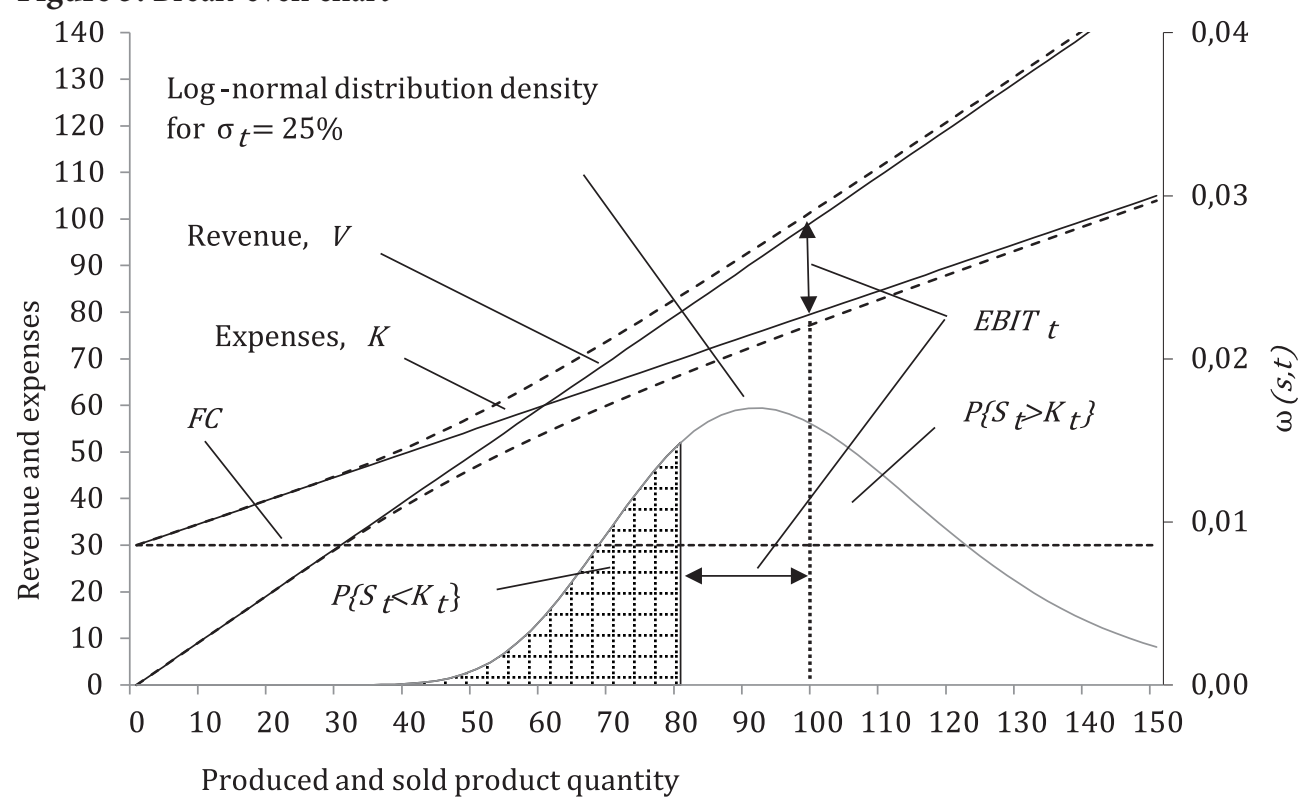

Figure 4. Profit and loss probability at the break-even point

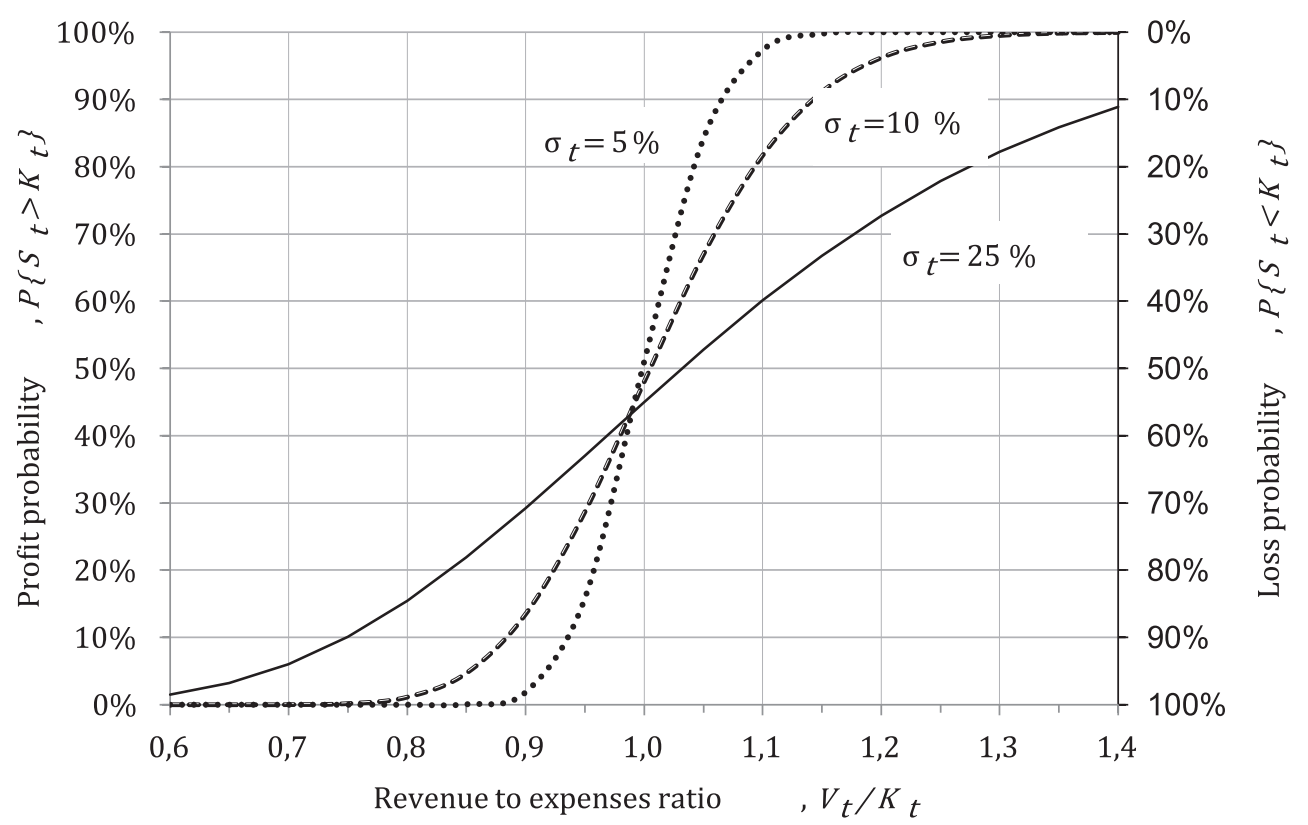

${ }^{5}$ Simulation conditions: $F C=30, V C=0.5 \cdot$ (product quantity), $V=1.0 \cdot$ (product quantity), break-even point $=60$, planned profit $E B I T t=20$, planned quantity of produced and sold products $V_{t}=100$. 
The probability density median $\omega(s, t)$ acts as a certain "true" revenue value [Ayvazyan et al., 1983, p. 178]. With this value of revenue, the following equality holds: $\mathrm{P}\{\mathrm{St}>$ $\mathrm{S} 0.5, \mathrm{t}\}=\mathrm{P}\{\mathrm{St}<\mathrm{S} 0.5, \mathrm{t}\}$. According to the properties of the log-normal distribution law, the median-to-mathematical expectation ratio is described by the following equation: $S_{0,5, t}=V_{t} \cdot \exp \left(-0,5 \cdot \sigma_{t}^{2}\right)$. The level of production and sales at which $K_{t}=S_{0,5, t}$ holds can be defined as the "true" breakeven point. In this case, one half of the operating cycles will result in revenue less than the costs incurred, and the other one - more.

When the standard deviation of the logarithm of the revenue growth rate is less than $13 \%$, an approximation is acceptable, at which the log-normal distribution law is replaced by a normal law [Vadzinsky, 2001, p. 190]. In this case, the shape of the distribution curve $\omega(s, t)$ approaches symmetric. The numerical characteristics of the density function differ slightly from each other: $V_{t} \approx S_{0,5, t} \approx \hat{S}_{t}$. The profit and loss probabilities at the break-even point are the same (see graphs $P\left\{S_{t}>K_{t}\right\}$ for $\sigma_{t}=5 \%$ and $\sigma_{t}=10 \%$ in Fig. 4).

\section{Econometric Analysis Example}

The uncertainty of revenue has an impact on all company performance, calculated on its basis. Now they should be considered as random variables. Therefore, instead of a uniquely defined value, we have a range of values. The probability of appearance of a certain value is determined by the distribution density. This has a significant effect on financial analysis. Instead of deterministic variables, the mathematical expectations of the corresponding random variables should be used.

\section{Empirical density function}

We will analyze the distribution density of the logarithm of the revenue growth rate of PJSC Aeroflot (Fig. 5) 6 . The relationship of the logarithm of the growth rate and the frequency that a certain value of the indicator appears is reflected in the histogram (actual distribution) and in the chart (theoretical distribution). The values of the random variable are represented by the logarithm of the ratio of the indicator for the current quarter to its value for the previous quarter. Before constructing of the histogram, the seasonal component was excluded. The calculations used the data of quarterly accounting reports for the period from 1999 to 2016.

Since we analyze the logarithms of the revenue growth rate, the theoretical distribution density is described by a normal law. The proximity of the actual and theoretical distributions indicates the validity of applying the geometric random motion model to describe the process of revenue generation. Furthermore, the correspondence of the distribution density of the logarithm of the revenue growth rate to the normal law is confirmed by the test performed by the quantile method (see Appendix 2).

\section{Operating cycle duration}

Figure 5. The distribution histogram of the logarithm of the revenue growth rate of PJSC Aeroflot

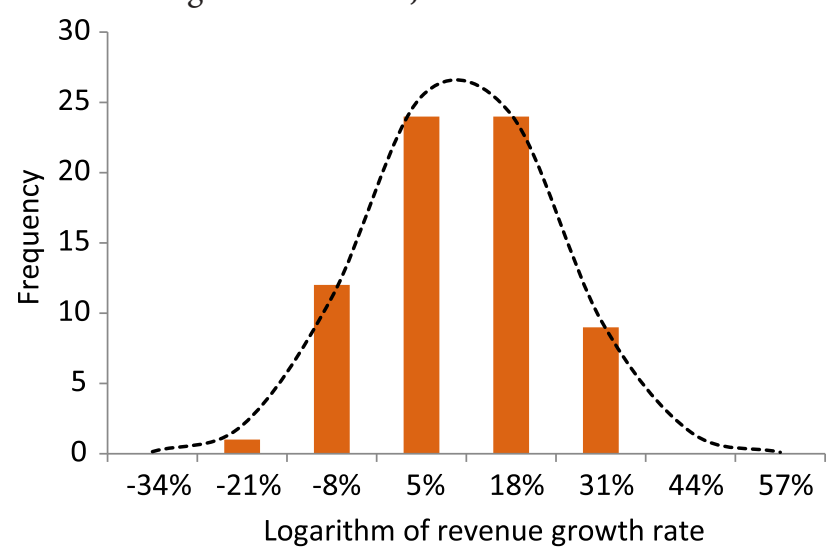

Note: the sample size - 70; the average - $4.2 \%$; the standard deviation - $13.3 \%$; Pearson's $\chi 2$ test with a significance level of 0.05-7.8; the observed value of the Pearson $\chi^{2}$ test is 1.8 (the hypothesis about the correspondence of the distributions is accepted).

The operating profit expected by the company, is made up of the financial results obtained upon completion of a number of operating cycles. Let us analyze the distribution of the operating cycle by duration (Fig. 6). The relationship between the duration of the operating cycle and the frequency that a certain value of the indicator appears is reflected in the histogram (actual distribution) and in the chart (theoretical distribution).

Figure 6. The distribution histogram of the duration of the operating cycle of PJSC Aeroflot

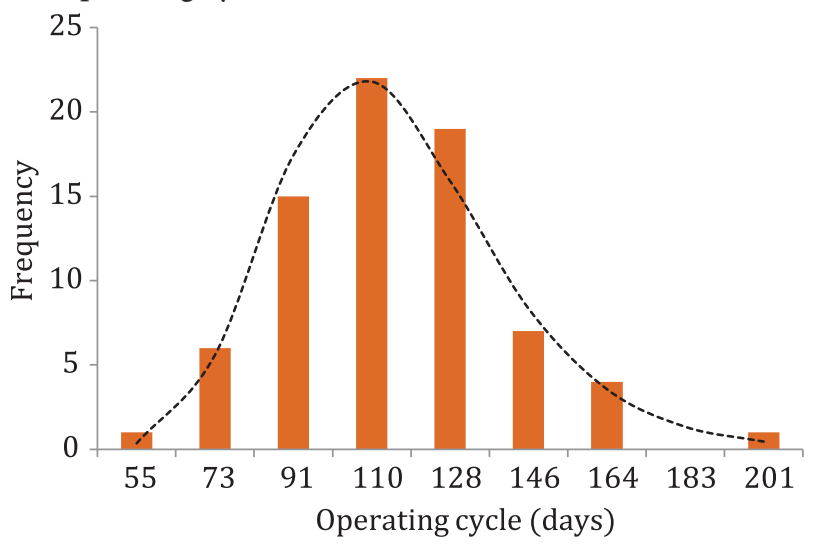

Note: the sample size is 75, the mode is 97 days, the median is 103 days, the average is 106 days, and the standard deviation is 26 days.

In constructing of the histogram, the company's quarterly accounting reports for the period from 1998 to 2016 were used. The average value of the operating cycle is equal to 106 days. We will be guided by this value in the future.

\footnotetext{
${ }^{6}$ Companies from capital-intensive industries are more susceptible to uncertainty, so we take the airline as an example. At present, Russian airlines are experiencing the consequences of the economic downturn that followed the rise in the level of uncertainty in 2008 [Zhdanov, Afanasyeva, 2011; Veremchuk, Chirkova, 2017].
} 
The theoretical distribution density of the indicator is described by a log-normal law [Belykh, 2018].

To calculate the duration of the operating cycle (in days), the following equation was applied:

Operating cycle $=\left(\frac{\text { Inventory }+ \text { VAT }}{\text { Cost }}+\frac{\text { Receivables }}{\text { Revenue }}\right) \cdot \frac{365}{4}$,

where the names of indicators in the numerator and denominator reflect the relevant items of the company's financial statements.

\section{Expected profit and loss values}

We will calculate the mathematical profit and loss expectations of PJSC Aeroflot. Suppose the company expects to generate revenue in the amount of $V_{t}=366$ billion rubles. In this case, the expenses, which consist of cost, commercial and administrative expenses, will amount to $\mathrm{Kt}=354$ billion rubles. (This is the actual data for 2015).

We use the break-even equation (1) and express the operating profit in terms of the ratio of revenues and costs associated with its generation:

$E B I T_{t}=V_{t}-K_{t}=366-354=12$ billion rubles

The ratio of standard deviations observed in practice is not accurately described by equation (8), which makes it better to obtain $\sigma_{t}$ empirically. To do this, it is necessary to assess the volatility of the growth rate of revenue generated over a period of time close to the duration of the operating cycle. Since the duration of the operating cycle of PJSC Aeroflot approximately corresponds to a quarter (106 days), we apply the value found for the logarithm of the quarterly revenue growth rate $\left(\sigma_{\text {кв }}=13.3 \%\right)$.

Suppose that in the planning of operating activities, seasonal fluctuations in revenue are taken into account. In this case, the equations for calculating the mathematical expectations (5) and (6) become as follows:

- Mathematical expectation of profit is:

$C_{t}=366 \cdot N\left(\frac{\ln \left(\frac{366}{354}\right)+\frac{0,133^{2}}{2}}{0,133}\right)-354 \cdot N\left(\frac{\ln \left(\frac{366}{354}\right)-\frac{0,133^{2}}{2}}{0,133}\right)=$

$=25,7$ billion rubles;

- Mathematical expectation of loss is:

$P_{t}=25,7-12,0=13,7$ billion rubles

We use the stochastic equation (4) and express the operating profit in terms of the "odds and risk" ratio associated with its generation:

$E B I T_{t}=C_{t}-P_{t}=25,7-13,7=12$ billion rubles

We see that the company's operating profit of 12 billion rubles is the result of the completion of a number of operating cycles, some of which end up with a positive financial result and generate a profit of 25.7 billion rubles, while others end up with a negative financial result and bring loss of $\$ 13.7$ billion rubles.

Thus, we calculated the financial result of operating activities in two ways. In the first case, we obtained an operating profit using a deterministic break-even equation (this way the profit is calculated in the process of the operational budget planning). In the second case, we obtained an operating profit using the stochastic break-even equation (this calculation shows the structure of the financial result in terms of favorable and unfavorable outcomes).

The second method of calculating the operating profit also makes it possible to calculate an indicator that can be used to assess the risk associated with the company's operating activities (see Appendix 3).

\section{Degree of operating leverage}

We will consider the distribution density of the degree of operating leverage (Fig. 7). The relationship between the degree of operating leverage and the frequency that a certain value of the indicator appears is reflected in the histogram. The data contained in annual accounting reports for the period from 1995 to 2015 were used in its construction. The sample includes 18 random variable values (the values of the degree of operational leverage were disregarded for two periods: for 2000 - equal to 29 and for 2002 - equal to 105). The average value of the degree of operating leverage is 0.7 . As can be seen from the histogram, the value obtained refers to the area of the most frequently appeared values of the indicator.

Figure 7. The distribution histogram of the degree of operating leverage of PJSC Aeroflot

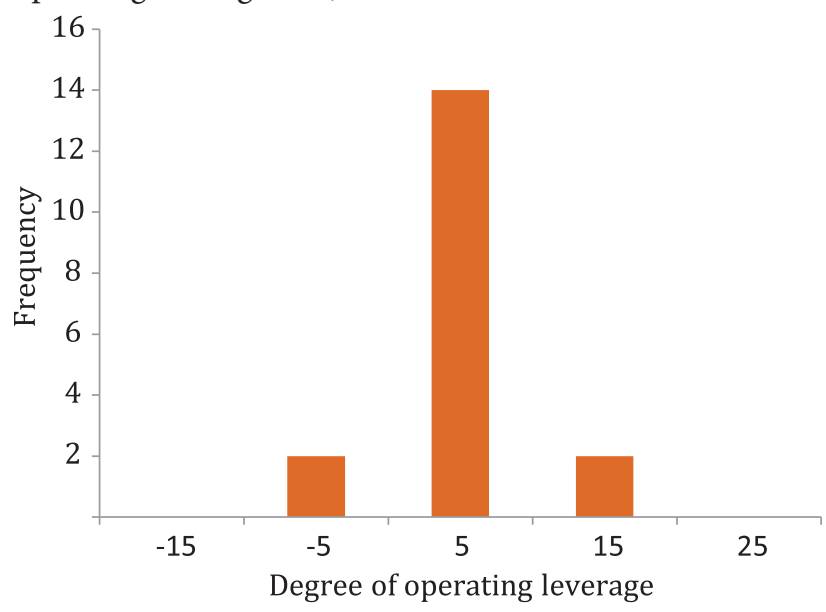

Note: the sample size - 18; the average - 0.71; the standard deviation - 5.36 .

To calculate the degree of operating leverage $(D O L)$, a method which analyzes the relative change in revenue and operating profit for two consecutive periods of time was used:

$D O L=\frac{\Delta E B I T / E B I T}{\Delta V / V}$,

where the value of operating profit is calculated without taking into account income and expenses not related to operating activities ${ }^{7}$.

The value of the degree of operating leverage less than 1 indicates a break of the linearity of the relationships that

${ }^{7}$ The method of calculating the degree of operating leverage is described in more detail in the work [Alekseev, Nikolaeva, 2016]. 
describe the change in revenue and expenses with an increase in production and sales. As a consequence, the measurement of the financial safety margin using a deterministic break-even equation becomes not an easy task. The method based on the stochastic break-even equation is more efficient. We see that with the existing revenue-to-expenses ratio $V_{t} / K_{t}=366 / 354=1.03$ and the standard deviation of the logarithm of the revenue growth rate $\sigma_{t}=13.3 \%$, the probability of loss remains quite high: $P\left\{S_{t}<K_{t}\right\}=43 \%$ (see Fig. 4). According to this, approximately two out of five operating cycles end up with a negative financial result.

\section{Conclusion}

The break-even equation describes the ratio of indicators of the company's performance at various levels of production and sales. The paper presents a mathematical model that complements the break-even analysis, which included the uncertainty associated with operating activities. Under this approach, the company's profit is considered in terms of favorable and unfavorable outcomes as a result of the implementation of one of these options. To describe a random process, we used a stochastic model based on a geometric walk. It follows that the distribution density of the revenue must be subject to a log-normal law. We used this circumstance to test the model by analyzing the empirical density function of the logarithm of the revenue growth rate of the selected enterprise.

To take into account the time factor, the concept of the operating cycle, in which the company's profit is considered as the result of a number of operating cycles, has been applied. One can imagine that the operational cycle corresponds to a test in probability theory, each of which can be completed with both positive and negative results. This method reveals the structure of the financial result in terms of possible favorable and unfavorable outcomes, including alternative scenarios of the company's development in the analysis. A loss incurred at the end of one operating cycle puts at risk the recurrence of the next operating cycle at the maintenance level. With such a review, it becomes evident that a source of financing not related to operating activities (for example, equity or overdraft loans) is required to ensure stable operation. The value of the expected loss gives an idea of the amount of such financing.

Uncertainty of demand leads to the fact that financial indicators calculated on the basis of revenue are random variables. Econometric analysis shows that the stochastic component is not irrelevant allowance, but the predominant component of the variables under study. In some cases, the distribution density is subject to a log-normal law. This is confirmed by histograms describing the distribution density of revenue and the duration of the operating cycle. Due to the asymmetry of the distribution curve, a single break-even point is not quite representative. This becomes particularly obvious with a high value of standard deviation. Conclusions made on the basis of the random nature of revenue may differ significantly from the results of a break-even analysis based on a deterministic approach.

The proposed method of break-even analysis is convenient to apply in practice. In the preparation of operating budget, sales and production budgets are simultaneously developed. At this stage, the mathematical expectations of both indicators necessary for evaluating a financial result using a stochastic equation become known. They are resistant to changes in accounting and management accounting methods: the value of revenue is dependent on the company's accounting policies to a minimum extent, while it is important to know the total value of expenses, without taking into account the classification used in the calculation. Despite the fact that the described mathematical model provides a good framework for the management of the company under uncertainty, it should be born in mind the ineffectiveness of tactical decisions that change the company's operating indicators in the right direction, but act within a short period of time. Not random (short-term), but trend changes, which are the result of strategic (long-term) efforts, are important.

\section{Appendix 1}

\section{Future option value}

To calculate the price of European options, equations which allow calculating their real value are used [Black, Scholes, 1973]:

- call option value:

$C_{0}=V_{0} \cdot N\left(d_{1}\right)-K_{t} \cdot N\left(d_{2}\right) \cdot e^{-\mu \cdot t} ;$

- $\quad$ put option value:

$P_{0}=V_{0} \cdot\left(N\left(d_{1}\right)-1\right)-K_{t} \cdot\left(N\left(d_{2}\right)-1\right) \cdot e^{-\mu \cdot t}$,

where $V_{0}$ is the current value of the financial asset; $K_{t}$ is the option exercise price;

$N\left(d_{1}\right)$ and $N\left(d_{2}\right)$ are integral functions of the normal distribution for arguments equal, respectively, to $d_{1}$ and $d_{2}$; $\mu$ is the risk-free rate of logarithmic return (at an annual rate $)^{8}$;

$t$ - option exercise period.

To take into account the value of money in time, we use the formula of continuous interest compounding: $V_{t}=V_{0} \cdot e^{\mu \cdot t}$

where $V_{t}$ is the value of the financial asset in time $t$. In much the same way, we calculate the future option value:

\footnotetext{
${ }^{8}$ The option model is based on the possibility of arbitrage transactions, for which reason the increase in the value of a financial asset is proportional to the change in the risk-free rate of return. When analyzing the operating activities, the return rate is equal to the weighted average cost of capital of the company.
} 
- call option value:

$C_{t}=C_{0} \cdot e^{\mu \cdot t}=V_{0} \cdot N\left(d_{1}\right) \cdot e^{\mu \cdot t}-$

$-K_{t} \cdot N\left(d_{2}\right)=V_{t} \cdot N\left(d_{1}\right)-K_{t} \cdot N\left(d_{2}\right)$;

- $\quad$ put option value:

$P_{t}=P_{0} \cdot e^{\mu \cdot t}=V_{0} \cdot\left(N\left(d_{1}\right)-1\right) \cdot e^{\mu \cdot t}-$

$-K_{t} \cdot\left(N\left(d_{2}\right)-1\right)=V_{t} \cdot\left(N\left(d_{1}\right)-1\right)-K_{t} \cdot\left(N\left(d_{2}\right)-1\right)$.

We transform the formulas for calculating the arguments of the integral functions of a normal distribution using the value of the financial asset at the time the option is exercised:

$d_{1}=\frac{\ln \left(\frac{V_{0}}{K_{t}}\right)+\mu \cdot t+\frac{\sigma_{t}^{2}}{2}}{\sigma_{t}}=\frac{\ln \left(\frac{V_{0}}{K_{t}} \cdot e^{\mu \cdot t}\right)+\frac{\sigma_{t}^{2}}{2}}{\sigma_{t}}=\frac{\ln \left(\frac{V_{t}}{K_{t}}\right)+\frac{\sigma_{t}^{2}}{2}}{\sigma_{t}}$,

$d_{2}=\frac{\ln \left(\frac{V_{t}}{K_{t}}\right)-\frac{\sigma_{t}^{2}}{2}}{\sigma_{t}}=d_{1}-\sigma_{t}$

where $\sigma_{t}$ is the standard deviation of the logarithm of the growth rate of the financial asset value for a period of time equal to $t$.

In this form, the equations describe option transactions in which the initial payment is made in the amount of the option's exercise price at current time $K_{0}$ : $K_{0}=K_{t} \cdot e^{-\mu \cdot t}$.

The final settlement is made in the amount of the future option value upon the exercise due date.

\section{Appendix 2}

\section{Verification of the Distribution Law}

For a long time, the log-normal distribution was applied mainly to describe the profitability of financial instruments [Shiryaev, 1998]. Currently there are works which show that the density of price distribution and rental rates in the real estate market can be described using this law [Laskin et al., 2016].

In accordance with the geometric random motion model, the distribution density of the revenue growth rate is also subject to a log-normal law. In order to verify this assumption, we consider the experimental data presented in the form of a quantile-quantile graph (Fig. 8). The graph show the theoretical distribution quantiles plotted on the abscissa, and the actual distribution quantiles plotted on the ordinate.

Experimental points are close to a straight line passing through the point $(0,0)$ at an angle of $45^{\circ}$. The nature of the deviation of the right end points indicates a possible negative asymmetry of the empirical distribution. Similar deviations are observed in analyzing the profitability of financial instruments [Hull, 2002, p. 335]. In general, the actual distribution density corresponds to theoretical assumptions, which confirms the possibility to use the method of calculating the mathematical profit and loss expectations described in the paper.
Figure 8. Quantile-quantile graph for the logarithm of the revenue growth rate of PJSC Aeroflot

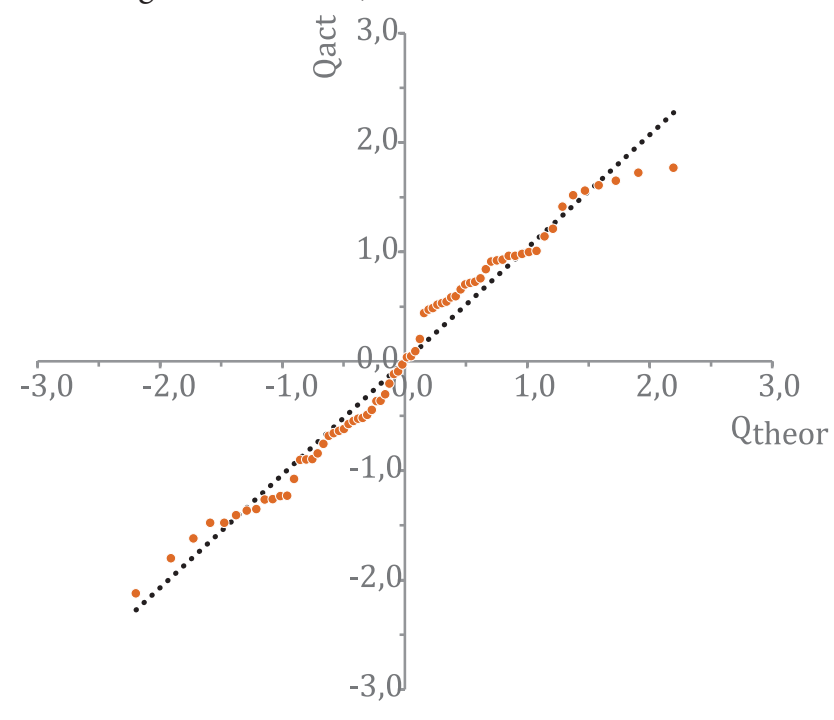

\section{Appendix 3}

\section{Risk-Adjusted Return on Capital}

In risk management, an indicator defined as risk-adjusted return on capital $(R A R O C)$ is used. It is equal to the ratio of net profit to capital reserved for possible losses [Lobanov, 2003, p. 557].

We calculate a similar indicator for capital, which provides the operating activities of PJSC Aeroflot. To this end, we find the ratio of operating profit minus income tax to the value of loss that goes with its receipt: $R A R O C^{\prime}=\frac{E B I T_{t} \cdot(1-d)}{P_{t}}=\frac{12 \cdot(1-0,2)}{13,7} \cdot 100=70 \%$ (year), where $d=20 \%$ is the income tax rate.

The resulting $R A R O C$ 'value shows the risk-adjusted operating return on capital. This indicator can be used to determine the optimum ratio of risk and profitability of the company's operating activities.

\section{References}

1. Aivazyan S.A., Enyukov I.S., Meshalkin L.D. Applied statistics. Basics of modeling and initial data processing. Moscow: Finansy i statistika; 1983. 471 p. (in Russ.).

2. Alekseev M.A., Nikolaeva N.Yu. The impact of non-operational income and expenditure on financial analysis using leverage theory. Ekonomika $i$ predprinimatel'stvo $=$ Journal of Economy and Entrepreneurship. 2016;(1-2):233-237. (in Russ.).

3. Belykh V.V. Current asset management: Uncertainty of the duration of the operational cycle. Problemy teorii i praktiki upravleniya $=$ Theoretical and Practical Aspects of Management. 2018;(2):85-94. (in Russ.).

4. Bloom N. Fluctuations in uncertainty. Journal of Economic Perspectives. 2014;28(2):153-176. DOI: 10.1257/jep.28.2.153 
5. Bukhvalov A.V. Real options in management: An introduction to the problem. Rossiiskii zhurnal menedzhmenta = Russian Management Journal. 2004;2(1):3-32. (in Russ.).

6. Bukhvalova V.V., Petrusevich A.V. Determination of the optimal production output under informational uncertainty of demand. Ekonomika i matematicheskie metody = Economics and Mathematical Methods. 2011;47(2):3-23. (in Russ.).

7. Vadzinskii R.N. Handbook of probabilistic distributions. St. Petersburg: Nauka; 2001. 296 p. (in Russ.).

8. Chirkova E.V., Veremchuk I.A. Preferences of creditors in the course of bankruptcy: Formal bankruptcy or restructuring (The case of "Transaero" Company). Rossiiskii zhurnal menedzhmenta $=$ Russian Management Journal. 2017;15(2):225-248. DOI: 10.21638/11701/spbu18.2017.205 (in Russ.).

9. Zhdanov V.Yu., Afanas'eva O.A. Bankruptcy risk diagnostics model for aviation enterprises. Korporativnye finansy = Journal of Corporate Finance Research. 2011;5(4):77-89. (in Russ.).

10. Laskin M.B., Rusakov O.V., Dzhaksumbaeva O.I. Estimation of the real estate market indexes according to statistical data and based on multidimensional log-normal distribution. Ekonomicheskii zhurnal Vysshei shkoly ekonomiki = The HSE Economic Journal. 2016;20(2):268-284. (in Russ.).

11. Lobanov A.A., Chugunov A.V., eds. Encyclopedia of financial risk management. Moscow: Alpina Publ.; 2003. 785 p. (in Russ.).

12. Madera A.G. Mathematical modeling and optimization of the business processes on the basis of a comprehensive criterion "chances - risks". Rossiiskii zhurnal menedzhmenta $=$ Russian Management Journal. 2015;13(4):51-68. (in Russ.).
13. Fedorova E.A., Timofeev Ya.V. Standards of financial stability of Russian enterprises: Sectoral features. Korporativnye finansy $=$ Journal of Corporate Finance Research. 2015;9(1):38-47. (in Russ.).

14. Shigaev A.I. The impact of changes in prices and costs on the break-even level of a company. Ekonomicheskii analiz: teoriya i praktika = Economic Analysis: Theory and Practice. 2008;(2):34-41. (in Russ.)

15. Shiryaev A.N. Fundamentals of stochastic financial mathematics. Vol. 1. Data. Models. Moscow: Fazis; 1998. 512 p. (in Russ.).

16. Black F., Scholes M. The pricing of options and corporate liabilities. Journal of Political Economy.1973;81(3):637-654. DOI: 10.1086/260062

17. Brennan M. J., Schwartz E. S. Evaluating natural resource investments. The Journal of Business. 1985;58(2):135-157. DOI: 10.1086/296288

18. Hull J.C. Options, futures, and other derivatives. Boston: Prentice-Hall; 2002. 826 p.

19. McDonald R., Siegel D. The value of waiting to invest. The Quarterly Journal of Economics. 1986;101(4):707727. DOI: $10.2307 / 1884175$

20. Merton R.C. On the pricing of corporate debt: The risk structure of interest rates. The Journal of Finance. 1974;29(2):449-470. DOI: 10.2307/2978814

21. Richards V.D., Laughlin E.J. A cash conversion cycle approach to liquidity analysis. Financial Management. 1980;9(1):32-38. 